\title{
ALGUNOS ASPECTOS DE LA DIALÉCTICA EN PLATÓN Y AGUSTÍN: PROYECCIÓN ACTUAL
}

María Teresa Calatroni*

SINTESE - Este trabajo es una serie de reflexiones personales acerca de la problemática dialéctica en Platón y Agustín, como también su proyección sobre el pensamiento actual. Fundamentalmente quisiera rescatar algunos conceptos a los que prestar especial atención: contingencia, apariencia, dualidad y negación que, aunque con diferentes alcances aparecen tanto en Platón como en Agustín, para culminar finalmente en la filosofía hegeliana. Por eso, he dividido mi ponencia en cuatro partes. Primero una introducción general, segundo, el tema de la dialéctica desde la lógica clásica, tercero el análisis de la dialéctica en Platón y en Agustín para, finalmente, proyectar algunas ideas e interpretaciones en función del pensamiento y la realidad del mundo actual.

PALABRAS-LLAVE - Platón, Agustín, Hegel, Dialéctica, contingencia, aperencia, dualidad, negación.
ABSTRACT - This work consists of a series of personal reflections the about of the dialectic problem in Plato and Augustine, as well as its projection on the current thought. Fundamentally I had wanted to rescue some concepts to the which we should pay special attention: contingency, appearance, duality and negation that, although with different reaches they appear so much in Plato as in Augustine, to culminate, finally, in the Hegel's philosophy. That, my placement is divided in four parts. First, a general introduction; second, the theme of the dialectic from the classic logic; third, the analysis of the dialectic in Plato and in Augustine for, finally, to project some ideas and interpretations in function of the thought and of the reality of the current world.

KEY WORDS - Plato, Augustine, Hegel, Dialectic, contingency, appearance, duality, negation.

\section{Presentación}

En base al marco teórico propuesto por el Dr. Carlos Cirne Lima, en virtud del cual el concepto de contingencia surge ya del cuadro de oposición de los juicios categóricos de Aristóteles, la contingencia forma parte de la lógica formal y la lógica dialéctica, no sólo no la contradice sino que la refuerza.

A partir de este supuesto, el autor analiza algunos aspectos de la tensión necesidad-contingencia, verdad-apariencia en Platón y en Agustín como relaciones dialécticas de implicación mutua para proyectarlas en el pensamiento actual.

* Departamento de Filosofia-Universidad J. F. Kennedy, Buenos Aires, Argentina

\begin{tabular}{|l|l|l|l|l|l|}
\hline VERITAS & Porto Alegre & v. 43 & $\mathrm{n}^{2} 4$ & Dezembro 1998 & p. 885-896 \\
\hline
\end{tabular}


La falta de cuestionamiento acerca de lo necesario y lo contingente impiden hoy la superación dialéctica del conflicto y conduce a un enfoque del hombre y de la sociedad donde la apariencia se transforma en realidad y ésta, simplemente en "virtual".

Revertir esta situación es el gran desafio que enfrenta hoy la filosofia como dialéctica.

\section{Introducción}

Etimológicamente la palabra "dialéctica" está compuesta por la raíz dia que denota la idea de separación, división, también está presente en el vocablo diálogo, el intercambio de opiniones y palabras que permite contraponer ideas y "mediar" entre ellas.

Tanto en el diálogo como en la dialéctica, se contraponen dos logoi y a través de esta contraposición que, necesariamente implica tensión, se produce en Platón y en Agustín, el ascenso de lo sensible a lo inteligible, de la apariencia a la realidad, de la contingencia a la necesidad.

Con anterioridad a Platón, el pensamiento de Heráclito puso de relieve el constante flujo de lo real y, a la vez, la función que desempeñan los contrarios. La dialéctica nace asociada a la conicepción metafisica según la cual la realidad es permanente cambio y movimiento, contraposición y síntesis de los contrarios. Esta sintesis es la que produce la "armonía", la contrapuesta armonía del arco y la lira, tal como queda consignada en el fragmento 51 de la enumeración de Dieis.

Pero para arribar a la "armonía" es necesaria la guerra, pólemos, como tensión y oposición de los contrarios, su génesis.

El propio Hegel lo reconoce cuando, con pathos de descubrimiento, al referirse a la dialéctica heraclítea afirma aquí divisamos tierra firme. Dialéctica que luego iba a sistematizar en su verdadera estructura y a erigir en el instrumento para dar cuenta de la experiencia y de su devenir en el dominio de la historia y en el de la naturaleza, concibiendo como "experiencia", el proceso de las cosas mismas, en la que va implicado el sujeto cognoscente.

De este modo, el método dialéctico surgirá como la acomodación del pensamiento a la manera en que transcurren los hechos reales. La única vía de acceso para penetrar y explicar la realidad, en la que todo se contrapone y compone, será la de contraponer y componer las ideas, los pensamientos.

Sería superfluo reseñar acá la larga historia de la dialéctica en la filosofía, pero sí destacar que desde ella, es posible entender la contingencia, la finitud y la apariencia como polos opuestos a necesidad, infinitud y realidad, pero mutuamente implicados.

\section{La Lógica tradicional y lạ Dialéctica}

Desde un punto de vista meramente formal, es erróneo pensar que en la lógica dialéctica pierden validez los principios de la lógica clásica, especialmente el principio de no contradicción. 
Para tratar este tema, he utilizado el enmarque teórico que del mismo realiza el Dr. Carlos Cirne Lima, en su trabajo Dialéctica y Evolución, cuando afirma que dentro de la lógica aristótelica late una concepción dialéctica, ya que de ella es posible extraer la noción de contingencia.

En el cuadro de oposición de los juicios categónicos, Aristóteles encuentra los juicios contrarios y los contradictorios. Si las contradictorias - AO, EI -, son mutuamente excluyentes en sus valores de verdad en la medida en que oponen en cantidad y calidad, es decir, si una es verdadera la otra será necesariamente falsa, no ocurre lo mismo con las contrarias.

Las contrarias A y E, se oponen sólo en calidad y si bien ambas no pueden ser verdaderas, si pueden ambas ser falsas.

El juicio contrario supone la carencia de la cualidad que se atribuye en el predicado, es decir, su negación predicativa y es aquí donde surge la indeterminación, más aún, la contingencia y con ella, la dialéctica, que es el juego de los contrarios, nunca de los contradictorios. O sea, que en el discurso dialéctico, tesis y antítesis pueden ser formuladas bajo la forma de proposiciones universales, unas positivas y otras negativas. De este modo, las proposiciones del tipo A constituirian la tesis y las del tipo E, la antítesis.

En las negativas, se trata de una ausencia, de una exclusión, pero de ello no es imposible suponer la existencia de un concepto no contemplado en ambos juicios, en la universal afirmativa y en la universal negativa. Surge pues una nueva y diferente posibilidad.

Como sostiene el Dr. Cirne Lima, este aspecto habia sido contemplado por los lógicos medievales cuando enunciaban las proposiciones reduplicativas o explicativas, es decir, cuando manteniendo el mismo sujeto se reduplica la proposición para entender un aspecto no contemplado.

La misma argumentación es claramente visible en el cuadro de oposición de los juicios modales. El subalterno del juicio apodíctico es un juicio problemático: la posibilidad de ser, pero también la de no ser. Si la problematicidad implica la posibilidad de ser, la contingencia supone la posibilidad de no ser, sin contradecir por ello ningún principio de la lógica clásica. Más aún, nace de ella como una derivación propia.

La contingencia del ente está en que es, que existe, pero que podria no haber existido, frente a la necesidad absoluta del ser que es y no puede no ser. Mientras que lo óntico es contingente y, por ende, cambiante, lo ontológico es necesario y permanente.

De este modo, en el corazón mismo de la lógica aristótelica está instalada la dialéctica y podría afirmarse con Octavio Paz en El arco y la lira que la lógica dialéctica es una tentativa de salvar los principios lógicos. ${ }^{1}$

$\mathrm{Al}$ analizar el silogismo aristótelico aparece también una concepción dialéctica implícita. Si se considera detenidamente la primera figura del silogismo a la que, en definitiva Aristóteles reduce todas las demás, término menor contenido en el término medio y éste en el mayor (Sócrates-hombre-mortal), surge la dialéctíca platónica que opera con la idea de métexis (participación). El eidos inferior está contenido en el eidos superior y se deduce de él, porque ya estaba puesto en él y se puede designar como hipótesis.

1 PAZ, Octavio. El arco y la lira. México, FCE, 1956, p. 100. 
El silogismo aristotélico está embebido de dialéctica platónica. Si no fuera entendido así, quedaría desprovisto de su verdadero sentido y convertido en un mero juego combinatorio. Deducir de la afirmación general "todos los hombres son mortales" que Sócrates también es mortal, resultaría totalmente superfluo. En cambio, si se entiende todo lo particular, no como un caso más de los registrados, sino como un individuo que participa de un determinado eidos, si la idea superior ni es deducida ni explicada a partir de lo singular, sino al revés, entonces adquiere pleno sentido el comprobar "fundado" en las premisas, lo que en ellas se deduce y desprende.

De este modo, el silogismo aristótelico y la lógica medieval tan criticada y menospreciada, no se convierten en un simple juego de combinaciones lógicas sino en un trozo de metafísica donde late la métexis platónica y, por ende, la dialéctica.

\section{Entre el exilio y el reino}

Contingencia y necesidad, cambio y devenir, apariencia y realidad y las relaciones de tensión entre ellos, son problemas permanentes que dieron origen tanto a la indagación cientifica como filosófica. El hombre como sujeto que se piensa a si mismo y al mundo, queda en el centro de esta guerra de contrarios en los que se juega su destino.

Por un lado, la necesidad del fundamento, la certeza que existe algo que permanece y que no cambia y, por otro, el devenir y la contingencia, que engloban al mundo y a la propia realidad del hombre, su existencia finita y perecedera que lo angustia y desconcierta.

Por esto he encabezado esta parte de la ponencia con el título antes indicado. Tanto en Platón como en Agustín, el hombre aparece exiliado, limitado, prisionero en el mundo de la apariencia. Pero su voluntad de querer conocer el fundamento y la explicación de su situación y condición, son el reino al que aspira y al que intenta acceder a través de la dialéctica.

El dudar acerca de la realidad de lo cotidiano, de lo habitual o, en lenguaje cristiano de lo terrenal, permite la posibilidad de su superación. En la medida en que el hombre reconozca su finitud, la precariedad de su existencia y, por ende, su contingencia, podrá iniciar la ascensión dialéctica al fundamento último y a la verdad.

\section{Platón}

A mi entender, la filosofia de Platón se centra en dos grandes temas: el problema del Bien y el de la verdad. Referirse a Platón es remitirse a la teoría de las Ideas pero, para introducirse en ella, es necesario analizar su concepto de verdad.

La verdad puede entenderse como verdad lógica, es decir, como una propiedad del pensamiento y del lenguaje, por la que nuestros juicios se conforman, en cuanto a su contenido, con la realidad que quieren expresar. Pero la verdad, también puede entenderse como verdad ontológica, como propiedad del ser. El ser es verdadero, en la medida en que es como debe ser. 
Platón es perfectamente consciente de estos dos conceptos de verdad, la verdad lógica y la ontológica pero, para él, es fundamental el segundo. La distinción entre un verdadero ser frente a un ente, o realidad que, por ser posible y por ende contingente, no es verdadero ser, por estar a medio camino entre el ser y no-ser, penetra toda la filosofia de Platón.

El presupuesto básico para ambos conceptos y significaciones de la verdad, reside en la convicción platónica que todo lo verdadero debe ser algo inmutable, necesario, siempre idéntico a si mismo, intemporal.

La búsqueda de esta verdad ontológica es el amor a la sabiduria, expresión con la que el platonismo define a la filosofía. El vocablo "búsqueda" implica, por cierto, tendencia, movimiento hacia, dirección con un fin determinado. Es una búsqueda anhelante de la verdad metafísica, búsqueda desde el mundo de la contingencia y la apariencia. En este buscar, el alma se conoce a si misma. Platón ha expresado su pensamiento sobre la verdad y la realidad, utilizando el símil de la caverna, en el libro VII de la República. ${ }^{2}$

El hombre cautivo, exiliado en el fondo de la caverna, toma por única realidad las sombras que se proyectan en la pared, hasta que se libera de su prisión y logra acceder a la auténtica realidad. El verdadero mundo es el de las Ideas, el mundo que de verdad es y cuyo conocimiento es liberador de la esclavitud.

El núcleo de esta comparación descansa sobre dos temas. Por un lado, la existencia de distintos estratos escalonados de ser y, por otro, que cada uno de ellos, se apoya en el inmediato superior. Así, el de las imágenes descansa sobre el del ser espacio-temporal del mundo físico real; éste, a su vez, en el del ser ideal. Aquello sobre lo que algo descansa o se apoya es, para Platón, la hipótesis, es decir, un ser que se ha de suponer para que se pueda fundamentar el otro.

También las ideas están en relación de fundamentación unas con otras. Las ideas subordinadas dependen de otras superiores que les sirven de fundamento y de soporte. En este proceso de fundamentación de ideas cada vez menos numerosas pero de mayor riqueza y poder de comprensión que las anteriores, Platón llega a la de mayor poder fundante, la idea de todas las ideas: la idea de Bien. Aquélla de las que todas dependen porque comprendiéndolas y como abarcándolas o sosteniéndolas, las fundamenta.

Como el sol en el mundo visible confiere ser a todo lo existente, asi deriva de la "idea de las ideas" el ser de los entes y la posibilidad de su cognoscibilidad.

La idea de Bien es el absoluto, que es por si, no por otro, la idea de Bien en si, a la que Platón había arribado también ascendiendo desde la problemática ética y haciendo converger en ella, suprema unidad, los dos grandes temas de su indagar filosófico.

En la doctrina platónica de la verdad se pone claramente de manifiesto la dialéctica intrínseca que la nutre. La distinción entre ser absoluto y contingente, distinción del ser a se y ser ab alio, el concepto de una ratio efficiens para todo ser $\mathrm{y}$ la exigencia de un supremo fundamento del mundo.

2 PLAtÓn. República, VII, 514 y ss. Buenos Aires, Editorial Eudeba, 1968, p. 381 y ss. 
Si en la metafísica platónica todo ser existe y recibe su inteligibilidad de la idea superior de la que depende, es natural que la tarea del filósofo sea la de esclarecer las ideas que están encerradas o implicadas en cada ser. Es la concepción de la verdad como alétheia, como descubrimiento, develamiento, desenmascaramiento del ser bajo la envoltura del ente. Es la explicación del ser mediante el logos como fundamento del ser. La dialéctica platónica tiene pues, una dimensión ontológica y metafisica.

Muchas veces, sin embargo, se suele ver sólo el lado lógico de la dialéctica. Es cierto que en sus últimos diálogos, Platón se interesó especialmente en el tema y también, que la idea platónica encierra una significación lógica.

Sin embargo, creo que a Platón le preocupó mucho más que los contenidos y las conexiones lógicas de las ideas, su visión metafísica, el logos como hipótesis, en el sentido griego, lo que fundamenta o funda, como soporte del ser. La dialéctica de Platón está incuestionablemente, al servicio de su metafísca.

Ello no significa que su interés por el aspecto lógico de la noción de verdad, sobre todo en los diálogos de su vejez, lo hayan conducido a una ruptura con su primera concepción filosófica. Más aún, esta continuidad de su pensamiento, es la que imprime el sello dialéctico subyacente en la lógica aristotélica a la que antes he hecho referencia.

La dialéctica platónica, como puede inferirse del libro VII de la República, ${ }^{3}$ es un itinerario del alma y la mente hacia la idea del Bien, al conocimiento del ser y de lo inteligible se accede sólo por la dialéctica.

En esta búsqueda del fundamento último, el hombre se expande a medida que su visión de la realidad se amplía. Lo que es evidente para su viva pasión, el "eros", su querer, se extiende a toda la voluntad humana y a todo anhelo hacia un bien necesario, que también puede ser formulado lógicamente.

A partir de este movimiento dinámico de todo el hombre, Platón distingue los cuatro planos o niveles, de acuerdo con su tipo de ser y de participación en la idea de Bien, planos que se corresponden con la realidad. De este modo, los órdenes y valores de estos estratos, son signos que apuntan a su incondicionalidad y total unidad, hacia su fundamento y, por ende, hacia su fin.

El ascenso dialéctico del alma, es la posibilidad de la liberación de la caverna, de la prisión que la encierra y encadena y exilia de la verdadera realidad. Por el impulso de su voluntad de querer y de su necesidad de lo absoluto, asciendo de eidos en eidos hasta lo no hipotético, lo que no necesita soporte o supuesto distinto de si.

Este viaje del alma desde la apariencia y la contingencia a lo inmutable y necesario, es una marcha larga y dificultosa, como el escarpado camino que deberá recorrer el prisionero para salir de la caverna. Sólo a partir de la ruptura de las cadenas de la contingencia y la apariencia, podrá remontarse hasta la luz del sol, la idea de Bien.

De este modo, la búsqueda de la verdad como alétheia, es el camino hacia la verdad y el ascenso ético hacia el Bien. Constituye la posibilidad de superar la contingencia, la multiplicidad, la apariencia, que culmina con la unicidad en la idea de Bien, de las dos grandes preocupaciones de Platón desde el inicio de su indagación filosófica: el tema gnoseológico y el tema ético.

3 PLATÓN. República, VI, 514 y ss. Buenos Aires, Editorial Eudeba, 1968, p. 383 y ss. 


\section{Agustín}

Su pensamiento, encuadrado dentro de la filosofía platónica y neoplatónica, tiene que resolver problemas nuevos que se plantean a partir de la necesidad de fundamentar una metafísica desde la visión cristiana del hombre y del mundo.

Estos problemas podrían sintetizarse en algunas preguntas fundamentales. ¿Qué es la verdad?. ¿Existe Dios y qué es? ¿Por qué se dio la creación, desde qué y cuándo? ¿Qué es el bien y por qué el mal y el pecado?

Lo mismo histórica que sistemáticamente la verdad, es el punto de partida de Agustín. Al percibir que ha estado en un error al caer en el maniqueísmo, la primera duda reside en saber si es posible la verdad. Agustín, como Platón, admite la existencia de verdades absolutas, pero no parte de verdades trascendentes como la filosofía anterior, sino de hechos de inmediata evidencia, de los datos de la conciencia, como luego hará Descartes.

A nadie le es dado dudar de la realidad que está presente en los datos de su conciencia y descubre, de este modo, una serie de verdades de la conciencia. Sin embargo, presupone una verdad que, en todo caso, es eterna y necesaria, diferenciando lo que es, de lo que se cree saber, a base de la sensación circunstancial que me proporciona la experiencia sensible.

Se plantea pues cuál es el origen de la verdad que, como en sus antecesores, Platón y Aristóteles no podía provenir únicamente de la experiencia sensible, en la medida en que sólo por el conocimiento de lo uno, puede pensarse lo múltiple. Nuevamente la tensión dialéctica entre lo uno como un polo y lo múltiple como el otro, con su implicación mutua.

Agustín coloca la fuente de la verdad, en el interior del espíritu del hombre, y sólo una vuelta hacia si mismo, hacia el interior de su alma, le permitirá descubrirla. Pero el origen de esta verdad interior aparece fundamentada en su "teoria de la iluminación". La verdad se irradia desde Dios al espíitu del hombre, aunque no se trata de una iluminación sobrenatural, sino de una revelación natural.

Del mismo modo que en Platón la idea de Bien, de la que las cosas participan es el sol que hace visibles todas las demás verdades, en Agustín, Dios es la luz que ilumina a todo hombre que viene a este mundo.

Es su concepción platonizante que ve siempre lo perfecto encubierto por lo imperfecto, la que opera en su pensar y le permite afirmar que detrás de toda verdad particular - que no es más que verdad participada - existe una verdad absoluta.

También Agustin admite la existencia de una verdad lógica, la del juicio, que consiste en la conformidad del enunciado con la efectiva realidad del objeto. De ella parte pero, - como Platón la trasciende -, para dejar en toda su luminosidad lo que es realmente el fundamento de la verdad, las ideas y razones eternas en el espíritu de Dios. La verdad coincide con ellas y ellas, las rationes, ideae, species aeternae, son las que constituyen el auténtico ser y la esencia de la verdad. Y puesto que estas ideas son de Dios y son Dios, puede afirmar que Dios es la verdad.

La verdad, como en Platón y Aristóteles, es la verdad ontológica, que trasciende la verdad lógica y le da sentido. 
El otro gran tema, la existencia de Dios, lo demuestra Agustín, como los demás Padres, desde la interioridad del alma humana, a través de la prueba noológica. El hombre descubre en si verdades eternas, perfectas, necesarias e inmutables frente a las cuales su actitud podrá ser diferente: rebeldía, despreocupación, o aceptación, pero que permanecen por encima de las actitudes que, frente a ellas asuma la conducta humana. No están en el espacio ni en el tiempo, son imperecederas y por ello no pertenecen a la existencia contingente, perecedera y finita del hombre.

Detrás de todo lo imperfecto está lo perfecto, detrás de lo contingente, lo absoluto, detrás de lo humano, lo trascendente, detrás del hombre, Dios. Un Dios que ha inscripto su ley y su verdad en el alma humana porque la ha creado a su imagen y semejanza.

Y es aquí donde aparece el tercer tema crucial para la filosofía cristiana: la creación, tema nuevo e inédito, sin arquetipos en el pensar anterior. ¿Por qué se dio la creación? No se puede dar otra razón mejor que la de que lo bueno debía ser creado por el Dios bueno; que es también la respuesta de Platón.

Pero acerca del origen del universo y del hombre, disienten ambos filósofos. Para Agustín no hay materia eterna. La materia, y el cosmos han sido creados por la voluntad divina de la nada, porque de otro modo seria introducir en la naturaleza de Dios, lo finito y lo mutable. Con esta afirmación se cierra toda posibilidad a la emanación y queda rota la ligazón con el neoplatonismo y potencializada la idea de la contingencia. Lo que existe pudo no haber existido. Dios no necesitaba la creación del mundo porque es necesario y perfecto. La creación pudo realizarse o no.

La otra gran pregunta es el "cuándo". Si Dios es intemporal y queda fuera del tiempo, crea el tiempo para el mundo y para el hombre. Tiempo finito, puesto que ha tenido origen y tendrá fin y con él el tiempo de la vida humana y de la cósmica.

Para quien quiera preguntar qué hacia Dios antes de la creación, es posible afirmar que tiene preparado un infierno para los que preguntan demasiado como responde Agustín en las Confesiones. ${ }^{4}$ O, como sostenía Lutero, que Dios estaba sentado detrás del avellano y tenía cortadas ramas para los que preguntaban demasiado.

Finalmente queda el tema del mal y con él, el del pecado, la desviación a la ley eterna grabada por Dios en el corazón del hombre.

Si Platón, por influencia de su maestro Sócrates, habia prestado especial atención al tema ético y al problema del Bien, no hace lo mismo con el del mal, el mal tanto en su sentido físico natural, como en su sentido moral. Platón calla sobre este problema, pero sin embargo, admite que el hombre es el responsable del mal moral.

Agustín, en cambio, partiendo de la idea de hombre caído, del pecado original, le dedica especial atención. Si Dios es la suma perfección y la suma bondad, el mal no puede provenir de El y si es perfecto tampoco pudo haber creado un hombre imperfecto, un ser que se incline por el mal.

4 AGUSTÍN. Confesiones, Libro XI, 12. México, Editorial Porrúa, 1986. 
Gran parte del texto de las Confesiones gira en torno al tema del mal, del dolor y de la muerte, que surgen como libre opción de la conducta humana que tiene libertad, "el libre arbitrio", para escoger entre los dos caminos que le han sido propuestos por su Creador. El tema del mal, derivado de la naturaleza caída, contingente, trae aparejada la muerte como castigo y también la tensión y la opción permanente entre el obrar bien y el obrar mal.

En Agustín no se obra mal porque no se sabe, el pecado surge de una decisión libre y voluntaria del hombre y con ello elimina la antigua convicción socrática y platónica "Sé sabio y serás bueno".

Pero al mismo tiempo, Agustín plantea por primera vez en el pensar occidental, el tema de la angustia, la angustia del hombre frente a su limitación temporal, la muerte, y a su destino eterno, el paraíso o el infierno. Vinculada con ella y con la idea de pecado, la culpa, que se genera a partir de su voluntad libre, al transgredir la ley moral.

De este modo, la dialéctica está inserta en el seno mismo de la filosofia agustiniana. Mientras que el ser eterno se posee a si mismo de una vez para siempre, el ser temporal, creado, está partido, dividido, se rehace siempre y así avanza hacia su ser a través de una lucha permanente entre dos contrarios: su aspiración final y sus exigencias terrenas.

Este hombre desdoblado, escindido puede rastrearse en las Confesiones que pese a estar construido como un monólogo, es en realidad un diálogo permanente entre el hombre interior que busca en si la respuesta divina por el fundamento y, el exterior que atiende a la realidad terrena.

También en Agustín como en Platón, el amor, el eros moviliza la aspiración de trascendencia, el traspasar el "exilio" de lo terreno y contingente para acceder al "reino" de lo eterno y permanente.

El último tema al que quisiera hacer referencia porque creo que es importante por sus derivaciones en el mundo de hoy, es el que se plantea en La ciudad de Dios. Es el mismo esquema que Agustín utiliza para explicar la tensión del hombre y que proyecta sobre la historia del mundo y de la sociedad.

Existen dos ciudades, la ciudad del hombre y la ciudad de Dios. Ambas expresan comunidades espirituales. La comunidad del orden - como armonía - como lo necesario, frente a la comunidad del caos, del desorden, de lo cambiante, finito y contingente. El ideal o el instinto. Tanto la igiesia como el estado, pueden alinearse en uno u otro orden, según la opción que realicen.

La ciudad del hombre edificada sobre un orden humano, puede y debe ser capaz de grandes realizaciones. Pero mientras sus fines estén dirigidos a los bienes terrenales de los que ansía gozar (frui) en lugar de usarlos (usi) para otro fin más allá de las apetencias, no es más que caos y desorden y sus valores serán pura ilusión.

La ciudad de Dios, en cambio, consta de hombres que entran en el orden armónico de lo necesario y final. No se sumergen en las cosas exteriores sólo para gozar de ellas o en ellas, sino que plantean sus objetivos en función de un orden ideal, necesario y fundante. 
Este es el sentido de la historia del mundo que se esconde y se contrapone en la tensión entre ambas ciudades. Una niega necesariamente a la otra, permanente tensión entre las fuerzas del bien y del mal, de lo contingente y lo necesario, del orden y del caos. Tema éste que luego retomará Hegel en sus "Lecciones acerca de la historia Universal".

Intentaré resumir las notas coincidentes en las interpretaciones de la dialéctica en Platón y Agustín. Por un lado la tensión dialéctica de la aspiración infinita y la experiencia finita. Por otro, la tensión entre lo que deberia ser y lo que es, lo que de hecho es dado y, finalmente, la posibilidad de la libre autodeterminación o del condicionamiento.

No en vano, mucho más tarde, Hegel acuñará su dialéctica de un modo original a raíz de sus tempranas meditaciones sobre la filosofía griega y el cristianismo y engloba rá en su filosofia todos los desarrollos dialécticos que le precedieron.

\section{La filosofia como indagación del Ser y como pensamiento crítico}

El fin del siglo nos enfrenta a una profunda problematización de nuestro ser hombre y de nuestro sistema de relaciones con el otro y con el mundo. No en vano estamos asistiendo a lo que se ha dado en llamar el ocaso de las ideas. Los sistemas conceptuales gravitan poco en el actual proceso de cambio histórico y de fundamentación y explicación de la realidad. Más aún, carentes de influencia, ni lo originan, ni lo orientan.

De la interpretación dialéctica de la historia hegeliana, se ha pasado a un cambio tecnológico: primero se producen los hechos, luego se elaboran - en base a ellos - las ideas que los explican. De este modo, no hay referentes para determinar la verdad o la falsedad. El concepto de verdad coincide con el concepto de hecho.

El qué y el por qué que, indagan y explican, inherentes al nacimiento de la filosofía y de la ciencia, han derivado en el "cómo", limitado al aquí y al ahora, donde la lógica de la eficacia y la utilidad, ha terminado desplazando los verdaderos cuestionamientos teóricos, no sólo en la vida social y política, sino que también, ha alcanzado el mundo de las ciencias y ciertas posiciones religiosas y filosóficas.

Este tomar partido por la acción en detrimento del conocimiento, esta negativa a cualquier ida y vuelta entre pensamiento y acción, conocimiento y experiencia, conduce - muchas veces - a una pasiva aceptación de la realidad como tal y a un simple acomodamiento a ella.

Por eso, se soslayan las preguntas, aquéllas que nacen de la razón crítica y cuestionadora y, se privilegian solamente las respuestas que se consideran eficaces para actuar, olvidando que un problema bien planteado está ya medio resuelto.

Siguiendo en parte el pensamiento heideggeriano, la inversión óntica del pensar ha conducido al hombre al olvido de la pregunta por el ser y a su sustitución por el ente. Pregunta ontológica que late en el pensamiento de Platón y Agustín porque sólo preguntando por el ser, es posible entender el ente. 
De este modo, el hombre como dasein, como ese ser que está ahí y que es en cada caso mio, para usar la terminología de Heidegger, y que se definía en su relación con el Ser, queda reducido a su dimensión entitativa óntica, de la que participan por igual cosas e instrumentos. El ser-ante-los-ojos se convierte en el ser-a-la mano, en el útil, que se valora por su eficacia instrumental.

El pensar ontológico, la posibilidad de entender la verdad como alétheia, como develamiento de lo oculto, es la posibilidad dialéctica que, a partir de la negación de la realidad contingente, puede superarla. Es el pensar en su función critica, problematizante y cuestionador.

El olvido ontológico, el no preguntarse acerca del ser - que es fundamento último -, ha conducido al uso calculista e instrumental de la razón y, por ende, a la razón subjetiva. A partir de aquí, esta razón subjetiva, instrumental, la razón tecnológica, disuelve su propio contenido objetivo y su énfasis cae más en los medios que en los fines, según Max Horkheimer. ${ }^{5}$

La razón crítica y el pensar se degradan y si Platón y Agustín trataron de buscar el fundamento último que otorga sentido a lo existente $\mathrm{y}$ a la vida humana dentro del cosmos, el mundo actual se caracteriza por estar fundado en "lo sin fundamento".

El imperativo de la cultura y del pensar actual, consiste en justificar aquéllo que existe, con independencia de su relación con la verdad y con el bien. De este modo, la filosofía como pensamiento cuestionador y crítico por excelencia, se degrada a una mera consolidación de lo existente, a la mera confirmación de un devenir histónico que parece acoger en si mismo su propia necesidad y validez.

El pensar ha roto con las raíces que le dieron origen: búsqueda de la verdad, angustia frente a las situaciones límite, dudas con respecto a las opiniones habituales, problemas del estado, como la justicia, por ejemplo, y los que derivan de las relaciones del hombre con lo trascendente.

La filosofia se enfrenta con un doble problema. Si, por un lado, debe responder a las profundas fracturas del espíitu de su época, por otro, debe oponerse a las tendencias banalizantes que encuentran en dichas fracturas, su propio justificativo.

Si tal como hemos planteado, una de las fracturas del pensar consiste hoy, en la falta de cuestionamientos esenciales, en el olvido de la pregunta por el ser y su sustitución por la del ente; la segunda tiene particular importancia en la medida en que imagen y realidad se confunden. Más aún, la verdadera realidad es la de la imagen.

Es aquí donde la concepción platónica adquiere una enorme vigencia. En Platón es clara la diferenciación entre los distintos estratos, el de las imágenes, el de los objetos sensibles que componen la realidad cotidiana, y el mundo de las ideas que los fundamenta.

En la sociedad actual, el poder de la imagen fundamenta la realidad, anulando y opacando la fundamentación teórica. La cultura de la imagen, especialmente la de la televisión y la propaganda, construyen una nueva realidad.

5 HORKHEIMER, Max. Crítica de la Razón Instrumental. Buenos Aires, Editorial Sur 1969, p. 21-25. 
Realidad diferente a la que crea el arte, que permite la libertad de acceso del espectador o del contemplador a un espacio y un tiempo propios y donde se sabe que se asiste a una ficción, o se enfrenta una realidad "compuesta" por el artista.

La imagen televisiva, compuesta y ordenada según criterios que responden a la eficacia, la utilidad o el rating de un programa, aparece como la única dimensión posible de la realidad. Es la realidad que se impone como tal al televidente. De allí su poder de fascinación y de presión sobre el público.

El "ver" algo por televisión es garantía para "saber" que algo ha sucedido, la importancia del hecho y las consecuencias que trae. ¿Quién puede dudar de algo que ha visto?

De este modo lo que despierta el deseo y moviliza la voluntad, el querer y con él, su posesión, no es la cosa o el objeto en si, sino su imagen proyectada, difundida y publicitada. Imágenes que diseñadas, difundidas y proyectadas globalmente, tienden a generar un todo semejante, idéntico, donde toda diferencia es negada y soslayada.

Precisamente, el gran desafío dialéctico del mundo actual, reside en la posibilidad de una integración cultural y económica en la sociedad global, conservando la historia particular y las modalidades específicas de las distintas comunidades que la integran. Mantener las diferencias dentro del todo.

El otro gran tema que quisiera rescatar, proviene del pensamiento de Agustín: la ciudad de Dios y la ciudad del mundo. Como ya se indiqué oportunamente, ambas son posibles dentro de la sociedad civil, en la medida en que el bien de utilidad (uti), de servicio público al todo, de finalidad social, esté rigiendo el bien de goce (frui), reservado a lo individual.

$\mathrm{Ni}$ el disfrute personal es enemigo de la utilidad, ni la finalidad social, del lógico y apetecible mejoramiento de la calidad de vida y del goce individual. Más aún, ambos se integran y se potencian mutuamente. Eliminado uno, desaparece el otro, o queda solamente el bien de goce, reducido a determinados grupos, violando los principios de la justicia distributiva.

El Estado, lo público, es de todos y para todos y como tal, deberá velar por los intereses comunes y fijar y mantener los valores de toda una sociedad, para diagramar y planificar sus políticas de desarrollo y crecimiento. Pero el todo esta compuesto por partes diferentes. Asegurar y garantizar las diferencias con sus derechos, sus valores y formas de vida, es una forma de integración ,sin homologarla a una masa indiferenciada.

Con respecto al papel del Estado como al ámbito de lo público y lo privado, la dialéctica y más específicamente Hegel, tiene todavía mucho por aportar.

La filosofía como pensamiento critico, como dialéctica, aparece como la única vía posible de comprensión del mundo de hoy y de sus posibles proyecciones para el próximo milenio, en la medida en que, a partir de la negación de lo actual, trate de superarlo en una sintesis integradora que, en la globalidad posibilite la diferencia, que en el todo, la parte otorgue la riqueza de sus modalidades específicas. 